\title{
Serum Concentration of Vancomycin Is a Diagnostic Predictor of Nephrotoxic Acute Kidney Injury in Septic Patients in Clinical and Surgical Wards
}

This article was published in the following Dove Press journal:

Infection and Drug Resistance

\author{
Welder Zamoner (D) \\ Isabella Gonçalves Pierri' \\ Karina Zanchetta Cardoso \\ Eid' \\ Lais Maria Bellaver de Almeida' \\ Adriano dos Santos ${ }^{2}$ \\ André Luís Balbi ${ }^{1}$ \\ Daniela Ponce'
}

'Botucatu School of Medicine, São Paulo State University - UNESP, Botucatu, São Paulo, Brazil; ${ }^{2}$ Clinics Hospital Pharmacy, Botucatu School of Medicine, Botucatu, São Paulo 186/8-970, Brazil
Correspondence: Welder Zamoner Tel +55 I4 982I 72334

Email welder.zamoner@unesp.br
Introduction and Aim: There have been few studies to evaluate the monitoring of plasmatic concentrations of vancomycin in septic patients and their association with acute kidney injury (AKI) and death. This study aimed to evaluate the prevalence of adequate, subtherapeutic, and toxic serum concentrations of vancomycin in hospitalized septic patients and to associate the adequacy of therapeutic monitoring with clinical outcomes.

Methodology: This was a cohort-unicentric study that evaluated septic patients aged $>18$ years using vancomycin admitted to clinical and surgical wards of a Brazilian university center from August 2016 to July 2017 in a daily and uninterrupted way. We excluded patients with AKI prior to the introduction of vancomycin or with AKI development $<48$ hours after use, patients with AKI of other etiologies, stage V chronic kidney disease, and pregnant women.

Results: We evaluated 225 patients, and 135 were included. Evaluation of serum concentration of vancomycin was realized in $94.1 \%$, and of those, $59.3 \%$ presented toxic concentrations. The prevalence of AKI was $27.4 \%$ and happened on average on the ninth day of vancomycin usage. Between the fourth and sixth days, vancomycin serum concentration of $>21.5 \mathrm{mg} / \mathrm{L}$ was a predictor of AKI, with area under the curve of 0.803 (95\% CI $0.62-0.98$, $p=0.005$ ), preceding the diagnosis of AKI by at least 3 days. Of these patients, $20.7 \%$ died, and serum concentrations of vancomycin between the fourth and sixth days were identified as risk factors associated with negative outcomes.

Conclusion: Serum concentration of vancomycin is an excellent predictor of AKI in patients admitted to wards, preceding the diagnosis of AKI by at least 72 hours. Toxic concentrations of vancomycin are associated with AKI, and AKI was a risk factor for death. Also, serum concentration of vancomycin $>21.5 \mathrm{mg} / \mathrm{L}$ was the only variable associated with death in the Cox model.

Keywords: sepsis, acute kidney injury, vancomycin, nephrotoxicity

\section{Introduction}

Sepsis is defined as an organic dysfunction that threatens life, caused by an exacerbated response to an infection. ${ }^{1,2}$ It implies the failure of multiple organs, including the kidneys. ${ }^{3-5}$ As such, the adoption of measures that lead to decreased mortality and reduced costs related to treatment and hospitalization, such as early administration of antimicrobials, the choice of which should be based on the patient's history, the recent use of antibiotics and the origin of the pathogens (community or hospital), are justified. ${ }^{6}$ 
The main polemic points on vancomycin relate to its efficacy and safety. ${ }^{5-9}$ Regarding efficacy, the concern is the alteration in pharmacokinetics, usually related to the distribution, metabolism, and elimination of the drug, ${ }^{6,8}$ which can lead to subtherapeutic concentrations, leading to the emergence of bacterial resistance due to the inefficacy of the treatment and consequently leading to higher mortality. Regarding safety, emphasis has been given to the main side effect of the medication - nephrotoxicity - which can aggravate the clinical picture and contribute to unfavorable outcomes.

Based on studies of animal and clinical experimentation, in 2009 it was determined that optimum activity occurs with an area under the curve divided by the minimum inhibitory concentration value of equal or greater than 400 . It was identified that this value is reached when trough serum concentrations of vancomycin (when the medicine is at a lower concentration) is 15-20 mg/L for major infections. ${ }^{10,11}$ However, there have been few studies to evaluate monitoring of its serum concentration and association with clinical outcomes, requiring improvement in knowledge regarding the safe and effective use of vancomycin.

\section{Methodology}

This was a prospective observational cohort study of adult patients diagnosed with sepsis defined using the quick SOFA $^{2}$ and admitted to four wards at the Clinics Hospital of Botucatu Medical School (two clinical and two surgical) during August 2016 to July 2017. Vancomycin was used according to the institution's protocols: loading dose of $25 \mathrm{mg} / \mathrm{kg}$ and maintenance of $15 \mathrm{mg} / \mathrm{kg}$, with dosing intervals of 12/12-96/ 96 hours, depending on the serum concentration of the antimicrobial. We excluded patients aged $<18$ years, pregnant patients, those with chronic kidney disease stage 5 (classified according to estimated serum-creatinine clearance or measured at $<15 \mathrm{~mL} / \mathrm{min}$ ), renal transplant recipients, patients already admitted with an acute kidney injury (AKI) of any etiology, vancomycin use $<48$ hours, and those who had developed AKI from another etiology (prerenal or ischemic, glomerular, and vascular renal causes).

The study was approved by the local research ethics committee and registered in the Brazilian Registry of Clinical Trials (ReBEC) under number RBR-4zrwtz. Patients or legal guardians signed the informed consent form. From the time of prescription of vancomycin, the patient was included in the study and their electronic medical record consulted, and daily evolution data obtained, always by the same observer, until the end of the use of vancomycin and its hospital outcome (discharge or death).

The AKI definitions used were those of the organization Kidney Disease: Improving Global Outcomes (KDIGO): ${ }^{5}$ baseline creatinine being the lowest value in 6 months if no prior data available or lower creatinine levels during hospitalization as long as the patient was not on dialysis. Therapeutic, subtherapeutic, and toxic serum concentrations were defined as two consecutive trough concentrations of $15-20 \mathrm{mg} / \mathrm{L},<15 \mathrm{mg} / \mathrm{L}$, and $>20 \mathrm{mg} / \mathrm{L}$, respectively.

Central tendency and dispersion were calculated as continuous and frequency values for the categorical variable and occurrence of AKI and death were established as dependent variables. ROC curves were built to evaluate the cutoff points for serum-vancomycin concentration as predictors of diagnosis and prognosis of AKI during T0-T2, T2-T4, and T4-T6. Areas under the curve of $0.7-0.79$ were considered satisfactory and $0.8-0.89$ as optimum. Sample-size calculation was performed using Lee's formula, and considering that the prevalence of AKI would be $20 \%$ higher in patients with toxic concentrations of vancomycin, with $\alpha$-error of 0.05 and $80 \%$ study power, 64 patients were estimated for each group (total 128: 64 with toxic concentrations and 64 without).

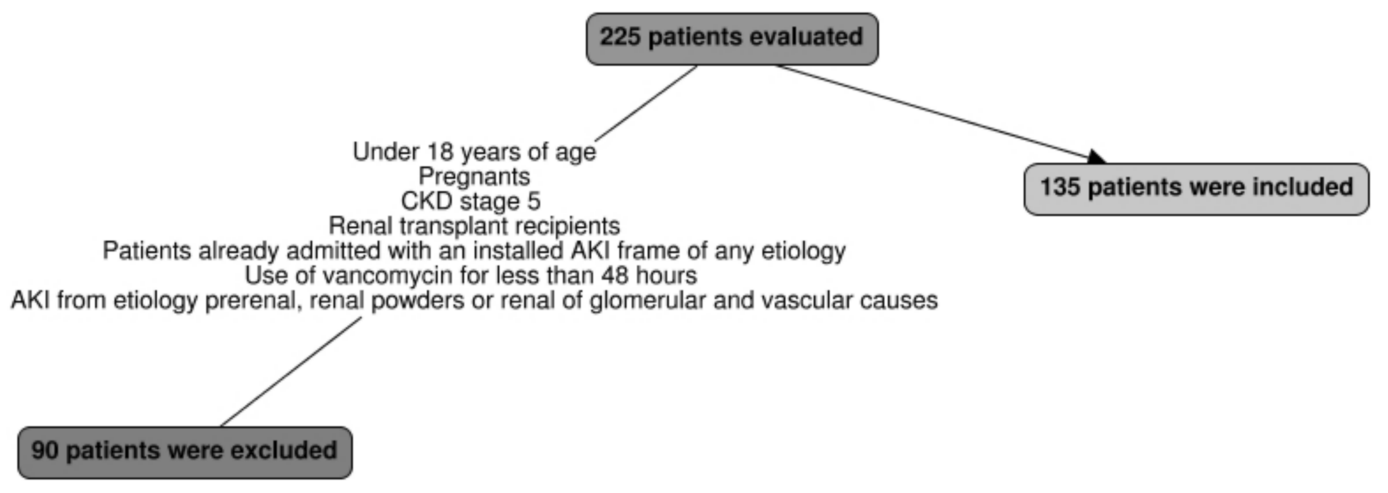

Figure I Flow diagram of patients included and excluded. 


\section{Results}

We included 135 patients from clinical and surgical wards (Figure 1), of which $94.1 \%$ had serum concentrations of vancomycin measured during the use of the antimicrobial. Of these, $75.6 \%$ received adjustments in dosage and $59.3 \%$ presented a toxic serum concentration of vancomycin. The mean higher value for serum concentration was $22.07 \pm 14.77 \mathrm{mg} / \mathrm{L}, 27.4 \%$ of the patients presented with AKI, of which KDIGO stage 1 was the most frequent (54.05\%), and $20.7 \%$ evolved to death.

Table 1 presents clinical and laboratory characteristics of the patients and Table 2 vancomycin-related characteristics, both regarding the presence of absence of AKI. n Cox regression analysis, serum concentration of vancomycin during 96144 hours (T4-T6, HR 1.06; $p=0.038$ ) was identified as the only risk factor for AKI, as indicated in Table 3 . The rest of the variables did not present statistically significant differences between the groups.

ROC-curve analysis (Figure 2) showed that serum concentration $>21.5 \mathrm{mg} / \mathrm{L}$ between the fourth and sixth days was a good predictor of AKI, with area under the curve of $0.8(95 \%$ CI $0.62-0.98$ ), sensitivity of $81.1 \%$, specificity of $73.7 \%$, and preceding diagnosis of AKI by at least 3 days (AKI happened on average at the ninth day of vancomycin use). After

Table I Clinical and Laboratory Characteristics of Patients Using Vancomycin Hospitalized in Surgical and Clinical Wards Regarding the Presence or Absence of AKI

\begin{tabular}{|c|c|c|c|c|}
\hline & General & with AKI & Without AKI & \multirow[t]{2}{*}{$p$-value } \\
\hline & $(n=135)$ & $(n=37)$ & $(n=98)$ & \\
\hline Age (years)* & $56.12 \pm 17.35$ & $56.03 \pm 17.5$ & $56.1 \pm 17.3$ & 0.836 \\
\hline Weight (kg)* & $65 \pm 16.4$ & $72.3 \pm 16.8$ & $65.6 \pm 15.8$ & 0.036 \\
\hline Male sex $(\%)$ & $93(68.9)$ & $28(75.6)$ & $65(66.3)$ & 0.402 \\
\hline GFR baseline (CKD-EPI), $\mathrm{mL} / \mathrm{min}^{*}$ & $106 \pm 25.7$ & $106.6 \pm 28.4$ & $108.5 \pm 24.7$ & 0.811 \\
\hline Arterial hypertension (\%) & $62(45.9)$ & $15(40.5)$ & $47(47.9)$ & 0.563 \\
\hline Diabetes mellitus (\%) & $44(32.6)$ & $13(35.13)$ & $31(31.63)$ & 0.856 \\
\hline CKD (\%) & $4(3)$ & I (2.7) & $3(3.06)$ & 1 \\
\hline CVD (\%) & $14(10.4)$ & $4(10.8 I)$ & $10(10.2)$ & 1 \\
\hline Mechanical ventilation (\%) & $12(8.9)$ & $10(27.03)$ & $2(2.04)$ & $<0.001$ \\
\hline Vasoactive drugs (\%) & II (8.I) & $7(18.9)$ & $4(4.08)$ & 0.014 \\
\hline Contrast (\%) & $21(15.6)$ & $6(16.2)$ & $15(15.3)$ & I \\
\hline Diuretic (\%) & $33(24.4)$ & $17(45.9)$ & $16(16.3)$ & 0.001 \\
\hline Other nephrotoxic drugs (\%) & $18(13.3)$ & $8(21.62)$ & $10(10.2)$ & 0.145 \\
\hline Hospitalization category & & & & 0.36 \\
\hline Surgical (\%) & $70(51.9)$ & $19(51.3)$ & $51(52.04)$ & \\
\hline Clinical (\%) & $65(48.1)$ & $32(49.5)$ & $33(50.8)$ & \\
\hline \multicolumn{5}{|l|}{ Hospitalization diagnostic } \\
\hline Infection (\%) & $76(53.6)$ & $15(40.5)$ & $61(62.2)$ & 0.038 \\
\hline Cardiovascular (\%) & $5(3.7)$ & $3(8.1)$ & $2(2.04)$ & 0.248 \\
\hline Postoperative (\%) & $28(20.7)$ & $8(21.62)$ & $20(20.4)$ & 1 \\
\hline Other (\%) & $26(19.3)$ & II (29.73) & $15(15.3)$ & - \\
\hline \multicolumn{5}{|l|}{ Infection focus } \\
\hline Cutaneous (\%) & $53(39.3)$ & $14(37.8)$ & 39 (39.7) & 0.992 \\
\hline Urine (\%) & $5(3.7)$ & - & $5(5.1)$ & 0.374 \\
\hline Blood (\%) & $4(3)$ & - & $4(4.08)$ & 0.497 \\
\hline Lungs (\%) & $27(20)$ & $9(24.3)$ & $18(18.3)$ & 0.596 \\
\hline Central nervous system (\%) & $21(15.6)$ & $6(16.2)$ & $15(15.3)$ & 1 \\
\hline Undetermined (\%) & $25(18.4)$ & $6(16.2)$ & $19(19.3)$ & 0.92 \\
\hline Hospitalization time (days)* & $22 \pm 16.2$ & $29.9 \pm 17.8$ & $24.27 \pm 15.3$ & 0.053 \\
\hline Death (\%) & $28(20.7)$ & 14 (37.8) & 14 (14.2) & 0.006 \\
\hline
\end{tabular}

Notes: *Mean \pm SD. Values in bold denote significance.

Abbreviations: GFR, glomerular filtration rate; CKD, chronic kidney disease; CVD, cardiovascular disease; AKI, acute kidney injury. 
Table 2 Characteristics Related to the Use of Vancomycin in Hospitalized Patients in Clinical and Surgical Wards Regarding the Presence or Absence of AKI

\begin{tabular}{|c|c|c|c|c|}
\hline \multirow[t]{2}{*}{ Variables } & \multirow{2}{*}{$\begin{array}{l}\text { General } \\
(n=135)\end{array}$} & \multirow{2}{*}{$\begin{array}{l}\text { with AKI } \\
(n=37)\end{array}$} & \multirow{2}{*}{$\begin{array}{l}\text { Without AKI } \\
(n=98)\end{array}$} & \multirow[t]{2}{*}{$p$-value } \\
\hline & & & & \\
\hline Vancomycin usage (days)* & $11 \pm 7.4$ & $13.14 \pm 7.7$ & $12.3 \pm 7.3$ & 0.478 \\
\hline Absolute attack dosage (mg)* & $1,500 \pm 394.4$ & $1,651.3 \pm 320.4$ & $1,513.01 \pm 4 \mid 4.1$ & 0.031 \\
\hline Attack dosage $(\mathrm{mg} / \mathrm{kg})^{*}$ & $24.3 \pm 6.2$ & $23.9 \pm 5.5$ & $23.3 \pm 6.6$ & 0.27 \\
\hline Mean maintenance dosage $(\mathrm{mg} / \mathrm{kg})^{*}$ & $16.9 \pm 5.6$ & $18.6 \pm 5.5$ & $16.2 \pm 5.6$ & 0.047 \\
\hline Dose adjustment $(\%)$ & $102(75.6)$ & $32(86.4)$ & $70(7 \mid .4)$ & 0.112 \\
\hline Number of dose adjustments* & $2 \pm 1.6$ & $2.38 \pm 1.7$ & $1.6 \pm 1.58$ & 0.021 \\
\hline Toxic serum concentration (\%) & $80(59.3)$ & $32(86.4)$ & 48 (48.9) & $<0.001$ \\
\hline Subtherapeutic serum concentration (\%) & $75(55.6)$ & $17(45.9)$ & $58(59.1)$ & 0.235 \\
\hline Higher value of vancomycin $(\mathrm{mg} / \mathrm{L}) *$ & $22.07 \pm 14.7$ & $32.6 \pm I 7.3$ & $20.8 \pm 12.3$ & $<0.001$ \\
\hline Vancomycin T0-T2 (mg/L)* & $13.14 \pm 6.9$ & $18.60 \pm 8.1$ & $10.85 \pm 5.2$ & 0.09 \\
\hline Vancomycin T2-T4 (mg/L)* & $11.9 \pm 11.6$ & $16.1 \pm 15.2$ & $11.3 \pm 10.18$ & 0.138 \\
\hline Vancomycin T4-T6 (mg/L)* & $17.93 \pm 7.94$ & $21.52 \pm 7.38$ & $16.50 \pm 7.77$ & 0.014 \\
\hline Vancomycin T6-T8 (mg/L)* & $21.33 \pm 10.97$ & $28.83 \pm I I .18$ & $17.95 \pm 7.14$ & 0.008 \\
\hline Number of collected serum concentrations* & $4 \pm 3.034$ & $4.46 \pm 3.07$ & $3.77 \pm 3.015$ & 0.171 \\
\hline
\end{tabular}

Notes: T0-T2, serum concentration between the start and the second day of usage of vancomycin ( $0-48$ hours); T2-T4, serum concentration between the second and fourth days of usage of vancomycin (48-96 hours); T4-T6:, serum concentration between the fourth and sixth days of usage of vancomycin (96-144 hours); T6-T8, serum concentration between the sixth and eighth days of usage of vancomycin (I44-192 hours). *Mean \pm SD. Values in bold denote significance.

Abbreviation: $\mathrm{AKI}$, acute kidney injury.

Table 3 Cox Regression of Variables Associated with the Presence of AKI in Patients Using Vancomycin Hospitalized in Clinical and Surgical Wards

\begin{tabular}{|l|l|l|l|}
\hline Variables & HR & $\mathbf{C l}$ & $\boldsymbol{p}$-value \\
\hline Number of adjustments & $\mathrm{I} .17$ & $0.91-1.5$ & $0.2 \mathrm{I}$ \\
Vasoactive drug & $\mathrm{I} .004$ & $0.96-1.2$ & 0.953 \\
Mechanical ventilation & $\mathrm{I} .007$ & $0.97-1.118$ & 0.947 \\
Attack dosage (mg) & $\mathrm{I} .00 \mathrm{I}$ & $\mathrm{I} .000-1.002$ & 0.87 \\
Vancomycin T4-T6 (mg/L) & $\mathbf{I . 0 6 4}$ & $\mathbf{I . 0 0 3 - I . I 2 8}$ & $\mathbf{0 . 0 3 8}$ \\
\hline
\end{tabular}

Notes: T4-T6, serum concentration between the fourth and sixth days of usage of vancomycin (96-144 hours). Values in bold denote significance.

construction of the free time curve for AKI, based on cutoff values obtained by the ROC curve fort 4-6 days, it was observed that in the group with serum concentrations $>$ $21.5 \mathrm{mg} / \mathrm{L}$, the free time for the development of AKI was smaller than the group with serum concentrations $<21.5 \mathrm{mg} / \mathrm{L}$ (log rank 0.026, Figure 3).

Table 4 presents clinical and laboratory characteristics of patients and Table 5 characteristics related to vancomycin, both regarding the outcome of death. After analysis of both groups through Cox regression, it was observed that serum concentration of vancomycin between the fourth and sixth days (HR 1,078, $p=0.039$ ), was the sole predictor of death, as shown in Table 6. After construction of the free time curve for death, based on the cutoff values obtained by the ROC curve for 4-6 days, it was observed that free time for death was smaller for the group with serum concentration $>21.5 \mathrm{mg} / \mathrm{L}$ than the group with serum concentration $<21.5 \mathrm{mg} / \mathrm{L}$ (log rank 0.006 , Figure 4).

\section{Discussion}

Despite vancomycin's ample use in clinical practice, two concerns still permeate its use: efficacy and safety. Regarding efficacy, it is known that there are alterations in the pharmacokinetics of septic patients, which may lead to subtherapeutic serum concentrations and emergence of bacterial resistance, with a possible increase in mortality. Regarding safety, focus has been put on its main collateral effect, nephrotoxicity, with risks of AKI and complications on the short and long term.

This cohort study had as an objective to evaluate the prevalence of monitorization of serum concentrations at adequate, subtherapeutic, and toxic levels, on top of analyzing the impact of the inadequacy of these serum levels on clinical outcomes, like development of AKI and mortality. Despite the literature about vancomycin being vast, there have been few studies to correlate serum levels with clinical outcomes.

A total of 225 patients were evaluated, but only 135 were included in the analysis. This reflects the difficulty of studying the role of nephrotoxicity of vancomycin, for it is 


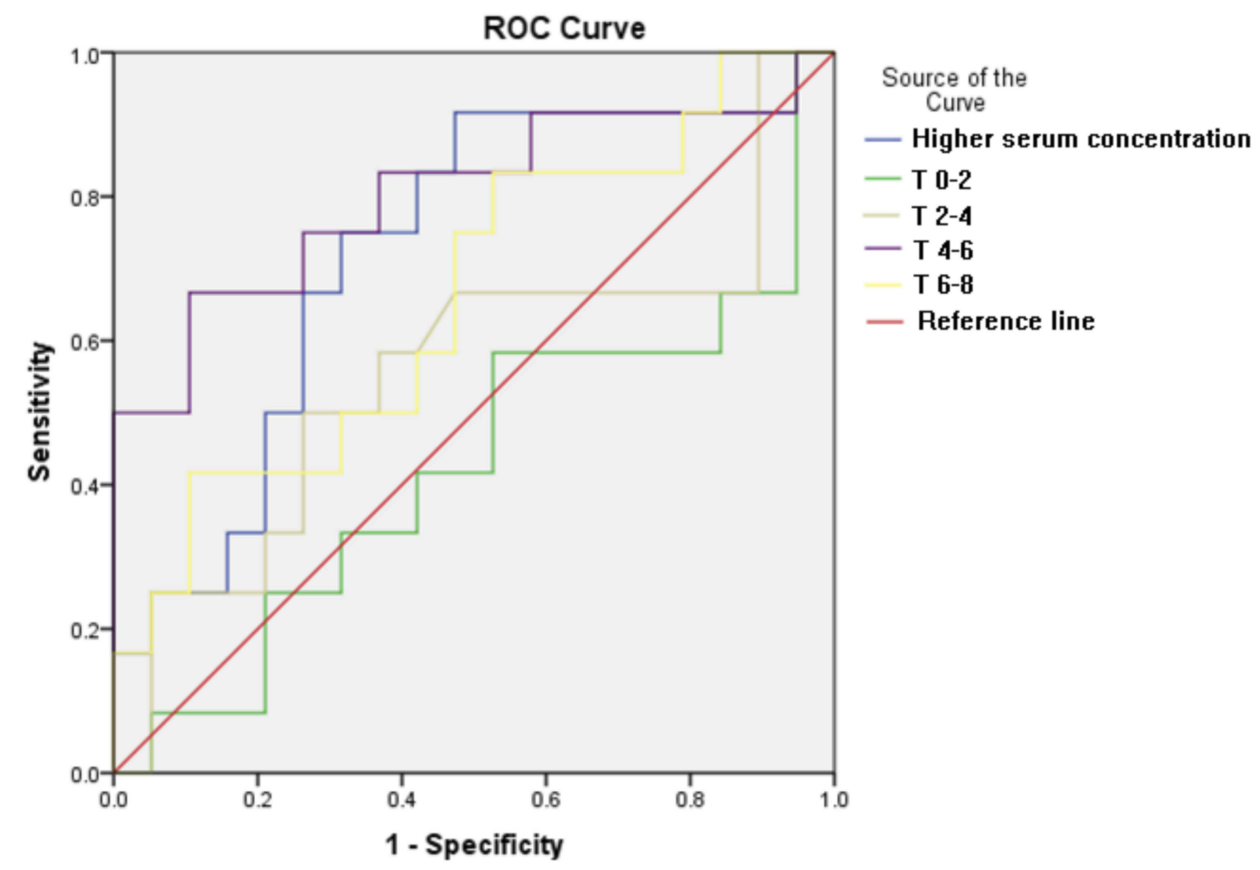

Figure 2 ROC curve for AKI outcome in septic patients using vancomycin hospitalized in clinical and surgical wards. T0-T2, serum concentration between the start and second day of usage of vancomycin (0-48 hours); T2-T4, serum concentration between the second and fourth days of usage of vancomycin (48-96 hours); T4-T6, serum concentration between the fourth and sixth days of usage of vancomycin (96-144 hours); T6-T8, serum concentration between the sixth and eighth days of usage of vancomycin (I44-192 hours).

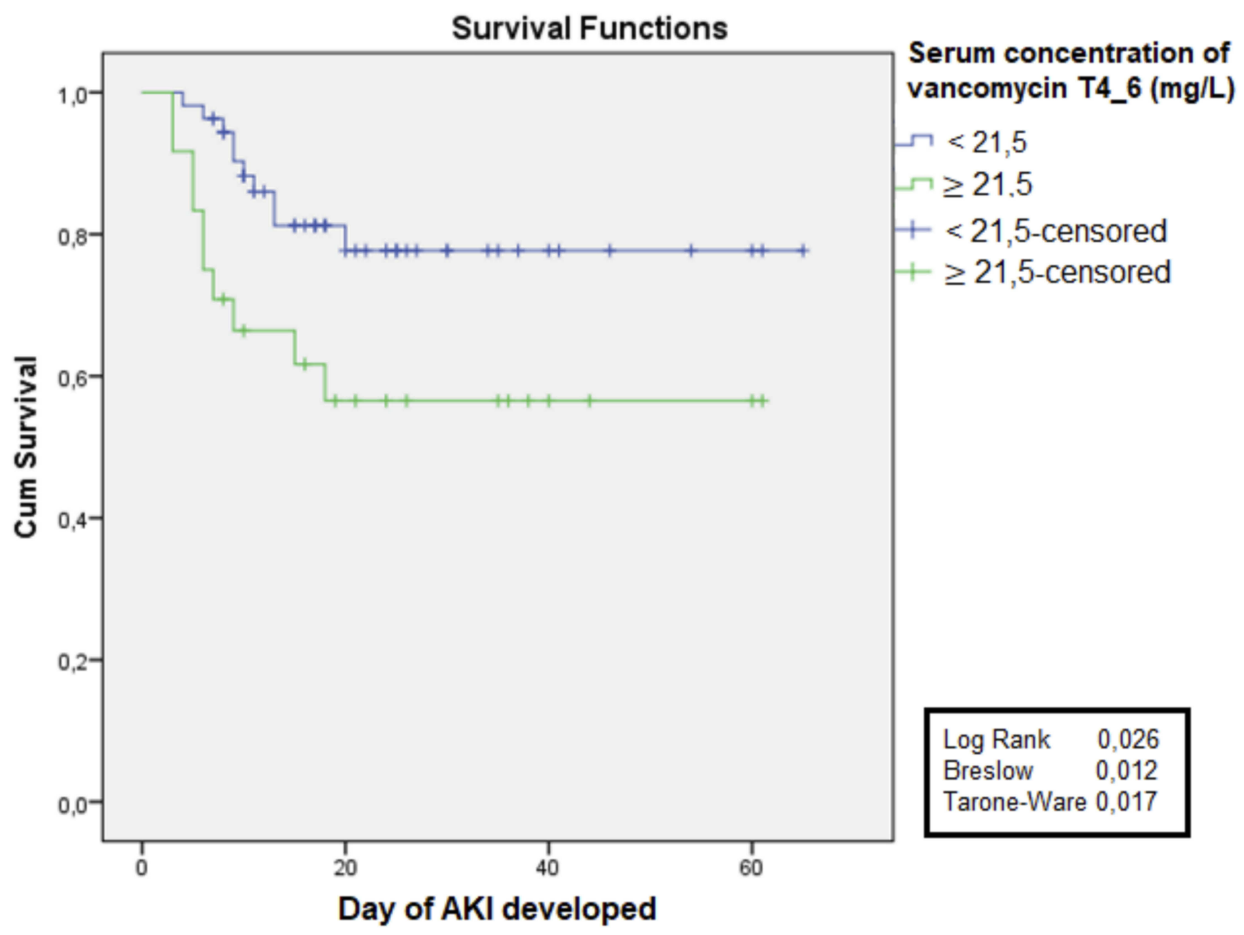

Figure 3 Free time for acute kidney injury (AKI) according to serum concentration (cutoff $21.5 \mathrm{mg} / \mathrm{L}$ ) during T4-T6 days (96-144 hours) for use of vancomycin in septic patients in clinical and surgical wards.

questionable if high serum levels of vancomycin are the cause (due to elevated serum concentration) or consequence of AKI (accumulation of the drug due to the impaired renal function from other injuries), as covered by the consensus of the American Society of Health-System Pharmacists, the Infectious Society of America, and the Society of 
Table 4 Clinical and Laboratory Characteristics of Patients Using Vancomycin Hospitalized in Clinical and Surgical Wards According to Outcomes

\begin{tabular}{|c|c|c|c|c|}
\hline & General & No Death & Death & \multirow[t]{2}{*}{$p$-value } \\
\hline & $(n=135)$ & $(n=107)$ & $(n=28)$ & \\
\hline Age (years)* & $60 \pm 17.3$ & $54.8 \pm 17.2$ & $61.1 \pm 17.1$ & 0.061 \\
\hline Weight $(\mathrm{kg})^{*}$ & $65 \pm 16.4$ & $67.3 \pm 16.2$ & $68.4 \pm 17.4$ & 0.783 \\
\hline Male sex (\%) & $93(68.9)$ & $71(66.3)$ & $22(78.5)$ & 0.311 \\
\hline GFR baseline (CKD-EPI)* & $106 \pm 25.7$ & $108.8 \pm 23.7$ & $104.6 \pm 25.7$ & 0.296 \\
\hline Arterial hypertension (\%) & $62(45.9)$ & $47(43.9)$ & $15(53.5)$ & 0.485 \\
\hline Diabetes mellitus (\%) & $44(32.6)$ & $39(36.4)$ & $5(17.8)$ & 0.101 \\
\hline CKD (\%) & $4(3)$ & $3(2.8)$ & I (3.5) & 1 \\
\hline CVD (\%) & $14(10.4)$ & $8(7.5)$ & $6(21.4)$ & 0.071 \\
\hline Mechanical ventilation (\%) & $12(8.9)$ & $7(6.5)$ & $5(17.8)$ & 0.134 \\
\hline Vasoactive drugs (\%) & II (8.1) & $5(4.6)$ & $6(21.4)$ & 0.013 \\
\hline Contrast (\%) & $21(15.6)$ & $19(17.7)$ & $2(7.1)$ & 0.277 \\
\hline Diuretic (\%) & $33(24.4)$ & $24(22.4)$ & $9(32.1)$ & 0.414 \\
\hline $\begin{array}{l}\text { Other nephrotoxic drugs \# } \\
\text { (\%) }\end{array}$ & $18(13.3)$ & $14(13.08)$ & $4(14.2)$ & 1 \\
\hline Hospitalization unit & & & & 0.003 \\
\hline Clinical (\%) & $65(48.1)$ & $44(4 I .1)$ & $21(75)$ & - \\
\hline Surgical (\%) & $70(51.9)$ & $63(58.8)$ & $7(25)$ & - \\
\hline Hospitalization diagnostic & & & & \\
\hline Infection (\%) & $76(53.6)$ & $60(56.07)$ & $16(57.1)$ & 1.00 \\
\hline Cardiovascular (\%) & $5(3.7)$ & $2(1.8)$ & $3(10.7)$ & 0.100 \\
\hline Postoperative (\%) & $28(20.7)$ & $25(23.36)$ & $3(10.7)$ & 0.227 \\
\hline Other (\%) & $26(19.3)$ & & & \\
\hline Infection focus & & & & \\
\hline Urine (\%) & $5(3.7)$ & $4(3.7)$ & I (3.5) & 1.00 \\
\hline Blood (\%) & $4(3)$ & $4(3.7)$ & 0 & 0.680 \\
\hline Lungs (\%) & $27(20)$ & $16(14.9)$ & $11(39.2)$ & 0.009 \\
\hline Abdomen (\%) & $6(4.4)$ & $4(3.7)$ & $2(7.1)$ & 0.616 \\
\hline Undetermined (\%) & $15(11.1)$ & $11(10.2)$ & $4(14.2)$ & 0.510 \\
\hline $\begin{array}{l}\text { Nephrological segment } \\
\text { (\%) }\end{array}$ & $13(9.6)$ & $7(6.5)$ & $6(21.4)$ & 0.044 \\
\hline $\begin{array}{l}\text { Hospitalization time } \\
\text { (days)* }\end{array}$ & $22 \pm 16.2$ & $26.09 \pm 16.3$ & $24.8 \pm 15.9$ & 0.658 \\
\hline $\begin{array}{l}\text { AKI (\%) } \\
\text { KDIGO (\%) }\end{array}$ & $37(27.4)$ & $23(21.5)$ & $14(50)$ & 0.006 \\
\hline 1 & $21(56.7)$ & $16(69.6)$ & $5(35.7)$ & 0.09 \\
\hline 2 & $7(19)$ & $4(17.4)$ & $3(21.4)$ & 0.316 \\
\hline 3 & $9(24.3)$ & $3(13)$ & $6(42.8)$ & 0.05 \\
\hline
\end{tabular}

Notes: *Mean \pm SD; ${ }^{*}$ nonhormonal anti-inflammatory, amphotericin B, acyclovir, amycacin. Values in bold denote significance.

Abbreviations: GFR, glomerular filtration rate; CKD, chronic kidney disease; CVD, cardiovascular disease; AKI, acute kidney injury.

Infectious Diseases Pharmacists. ${ }^{11}$ Therefore, one of the exclusion criteria of this study was the presence of AKI before the use of vancomycin or at 48 hours after starting its use.

In sum, $75.6 \%$ of the patients had their antimicrobial doses adjusted, with the mean number of realized adjustments being $2 \pm 1.65$. Iwamoto et al ${ }^{12}$ noticed that patients
Table 5 Characteristics Related to the Use of Vancomycin in Hospitalized Patients on Surgical and Clinical Wards Regarding Outcome

\begin{tabular}{|c|c|c|c|c|}
\hline & General & No Death & Death & \multirow[t]{2}{*}{$p$-value } \\
\hline & $(n=135)$ & $(n=107)$ & $(n=28)$ & \\
\hline $\begin{array}{l}\text { Time of usage of } \\
\text { vancomycin (days)* }\end{array}$ & $11 \pm 7.4$ & $13.3 \pm 7.5$ & $9.5 \pm 6.07$ & 0.016 \\
\hline $\begin{array}{l}\text { Absolute attack dosage } \\
(\mathrm{mg})^{*}\end{array}$ & $1,500 \pm 394.4$ & $\begin{array}{l}1,554.6 \\
\pm 407.1\end{array}$ & $\begin{array}{l}1,536.6 \\
\pm 347.9\end{array}$ & 0.962 \\
\hline Attack dosage $(\mathrm{mg} / \mathrm{kg})^{*}$ & $24.311 \pm 6.3$ & $23.52 \pm 6.4$ & $23.59 \pm 6.02$ & 0.847 \\
\hline $\begin{array}{l}\text { Mean maintenance } \\
\text { dose }(\mathrm{mg} / \mathrm{kg})^{*}\end{array}$ & $16.9 \pm 5.7$ & $18.02 \pm 5.5$ & $17.6 \pm 6.5$ & 0.422 \\
\hline Dose adjustment (\%) & $102(75.6)$ & $82(76.6)$ & $20(71.4)$ & 0.746 \\
\hline $\begin{array}{l}\text { Number of dose } \\
\text { adjustments* }\end{array}$ & $2 \pm 1.6$ & $1.8 \pm 1.6$ & $1.9 \pm 1.7$ & 0.87 \\
\hline $\begin{array}{l}\text { Toxic serum } \\
\text { concentrations (\%) }\end{array}$ & $80(59.3)$ & $62(57.9)$ & $18(64.2)$ & 0.695 \\
\hline $\begin{array}{l}\text { Subtherapeutic serum } \\
\text { concentrations (\%) }\end{array}$ & $75(55.6)$ & 61 (57.01) & $14(50)$ & 0.652 \\
\hline $\begin{array}{l}\text { Higher serum } \\
\text { concentrations }(\mathrm{mg} / \mathrm{L})^{*}\end{array}$ & $22.07 \pm 14.7$ & $23.3 \pm 13.8$ & $27.06 \pm 17.8$ & 0.229 \\
\hline $\begin{array}{l}\text { Vancomycin T0-T2 } \\
(\mathrm{mg} / \mathrm{L})^{*}\end{array}$ & $13.1 \pm 6.9$ & $12.3 \pm 6.9$ & $18.03 \pm 6.9$ & 0.324 \\
\hline $\begin{array}{l}\text { Vancomycin T2-T4 } \\
(\mathrm{mg} / \mathrm{L})^{*}\end{array}$ & $11.6 \pm 11.9$ & $11.9 \pm 10.2$ & $15.3 \pm 16.8$ & 0.677 \\
\hline $\begin{array}{l}\text { Vancomycin T4-T6 } \\
(\mathrm{mg} / \mathrm{L})^{*}\end{array}$ & $17.9 \pm 7.9$ & $16.5 \pm 7.1$ & $22.7 \pm 9.1$ & 0.005 \\
\hline $\begin{array}{l}\text { Vancomycin T6-T8 } \\
(\mathrm{mg} / \mathrm{L})^{*}\end{array}$ & $9.29 \pm 11.9$ & $9.96 \pm 11.7$ & $6.71 \pm 12.5$ & 0.064 \\
\hline $\begin{array}{l}\text { Number of collected } \\
\text { serum concentrations* }\end{array}$ & $4 \pm 3.03$ & $4.07 \pm 3.04$ & $3.54 \pm 3.02$ & 0.29 \\
\hline
\end{tabular}

Notes: *Mean \pm SD. T0-T2, serum concentration between the start and second day of usage of vancomycin (0-48 hours); T2-T4: serum concentration between the second and fourth days of usage of vancomycin (48-96 hours); T4-T6: serum concentration between the fourth and sixth days of usage of vancomycin (96-144 hours); T6-T8: serum concentration between the sixth and eighth days of usage of vancomycin (144-192 hours). Values in bold denote significance.

that were not submitted to monitoring of therapeutic concentrations of vancomycin presented a significant reduction in depuration values of creatinine and thus higher risk of nephrotoxicity than those that were monitored (OR $0.25, p<0.05$ ). Davis et $\mathrm{al}^{13}$ evaluated adherence to guidelines instituted by the consensus of $2009^{11}$ regarding the use of vancomycin, and showed that despite the recommendations, only $19 \%$ of institutions questioned claimed to use a standard definition to identify vancomycinassociated nephrotoxicity.

Despite having the availability to realize therapeutic monitoring of the drug, which is not unanimous in all centers, difficulties have been observed with reaching and sustaining adequate serum concentrations, due to factors related to collection, patients, and pharmacokinetic variation of the drug in septic patients. ${ }^{8}$ In our study, this 
Table 6 Cox Regression of Variables Associated with Death in Patients Using Vancomycin Hospitalized in Clinical and Surgical Wards

\begin{tabular}{|l|l|l|l|}
\hline & HR & Cl & p-value \\
\hline Diabetes mellitus & 2.434 & $0.637-9.294$ & 0.193 \\
SOFA score & 1.169 & $0.99-1.38$ & 0.066 \\
Serum concentration, & $\mathbf{1 . 0 7 8}$ & $\mathbf{I . 0 0 4 - 1 . 1 5 7}$ & $\mathbf{0 . 0 3 9}$ \\
T4-T6 days (mg/L) & & & \\
Age & 0.992 & $0.959-1.025$ & 0.63 \\
$\begin{array}{l}\text { Follow-up with nephrologist } \\
\text { (due to AKI) }\end{array}$ & 0.934 & $0.243-3.584$ & 0.92 \\
\hline
\end{tabular}

Notes: T4-T6, serum concentration between the fourth and sixth days of usage of vancomycin (96-144 hours). Values in bold denote significance.

Abbreviation: AKI, acute kidney injury.

difficulty was also present, with elevated rates of subtherapeutic and toxic concentrations.

The incidence of AKI found in this study was $27.4 \%$, which happened on average 9 days after the start of usage of vancomycin, with mortality of $20.7 \%$. Data from the literature suggest variable nephrotoxicity prevalence: from $5 \%$ to $40 \%$ in the presence of other nephrotoxins in concomitant use. $^{11,14-16}$ On Cox regression analysis, only the higher value of serum concentration between the fourth and sixth days was a factor associated with the development of AKI in this population, with serum concentration $>21.5 \mathrm{mg} / \mathrm{L}$ showing to be a good predictor of AKI, with an area under the curve of 0.8 , sensitivity of $81.1 \%$, specificity of $73.7 \%$, and preceding the diagnoss of AKI by 3 days (AKI happened on average on the ninth day of use of vancomycin).

A prospective multicentric study conducted by Bosso et al $^{17}$ evaluating 288 patients using vancomycin found an association between nephrotoxicity incidence and vancomycin concentrations, with AKI occurring in $29.6 \%$ of patients with serum concentrations of vancomycin $>15 \mathrm{mg} / \mathrm{L}$ and $8.9 \%$ of patients with vancomycin concentrations $<15 \mathrm{mg} / \mathrm{L}$. Ten other studies reviewed by Gupta et $\mathrm{al}^{16}$ identified concentrations of vancomycin $>15 \mathrm{mg} / \mathrm{L}$ as a predictor of nephrotoxicity, with AKI incidence of $27 \%$. As such, the ideal therapeutic concentrations aimed at preventing nephrotoxic AKI are questionable. On Cox regression analysis, the higher concentration of vancomycin between the fourth and sixth days was the only predictor of death in the population.

This study presents some limitations, such as the small sample obtained, reflecting the difficulty of studying nephrotoxicity; the data being obtained from a single center; the fact of bacterial vancomycin resistance not having being studied; and the role of serum concentration as a prognostic predictor of AKI (eg, gravity and necessity of acute renal support). Despite these limitations, it was the first study to present cutoff

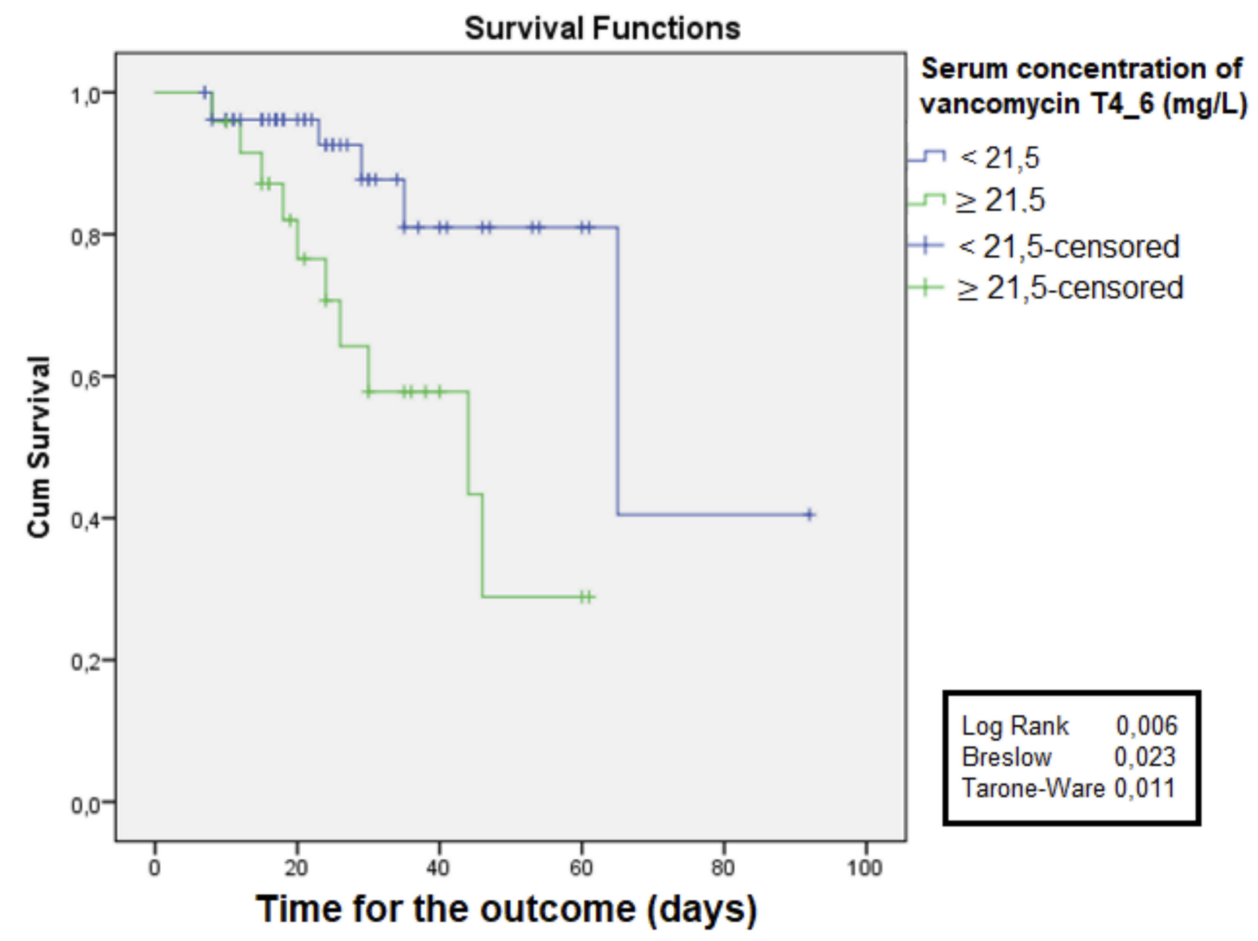

Figure 4 Free time for death outcome according to serum concentration (cutoff $21.5 \mathrm{mg} / \mathrm{L}$ ) during T4-T6 for vancomycin in patients hospitalized in surgical and clinical wards. T4-T6, serum concentration between the fourth and sixth days of usage of vancomycin (96-144 hours). 
values with an objective of refining the use and monitoring of vancomycin in septic patients in clinical and surgical wards.

\section{Conclusion}

This study showed that the prevalence of AKI associated with the use of serum concentration of vancomycin was elevated and that serum concentrations $>21.5 \mathrm{mg} / \mathrm{L}$ between the fourth and sixth days were an independent predictor of $\mathrm{AKI}$, presenting sensitivity and specificity $>80 \%$ and preceding AKI diagnostis by at least 3 days. It was also shown to be associated with death on uni- and multivariate analysis, remaining the single predictor of death even after adjustment by the Cox model for the variables that also showed statistical significance. Therefore, early identification of serum concentrations of vancomycin can make adequate therapeutic interventions possible, eg, with adjustment of doses or administration intervals, with the goal of preventing AKI or modifying its natural history, resulting in a possible reduction in mortality.

\section{Human Rights}

This study was approved by the Ethics Committee of the Brazil Platform under number 65827117.4.0000.5411.

\section{Informed Consent}

Participants provided written informed consent to participate at the time of enrollment. Data were anonymized for privacy. The study was conducted according to good clinical practice and the Declaration of Helsinki, and was registered in the Brazilian Registry of Clinical Trials (ReBEC) under number RBR-4zrwtz.

\section{Data-Sharing Statement}

No further data will be shared.

\section{Disclosure}

The authors have declared they have no conflicts of interest.

\section{References}

1. Lentini P, De Cal M, Clementi A, D’Angelo A, Ronco C. Sepsis and AKI in ICU patients: the role of plasma biomarkers. Crit Care Res Pract. 2012;2012:1-5. doi:10.1155/2012/856401
2. Singer M, Deutschman CS, Seymour CW, et al. The third international consensus definitions for sepsis and septic shock (Sepsis3). JAMA. 2016;315(8):801-810. doi:10.1001/jama.2016.028

3. Schier RW, Wang W. Acute renal failure and sepsis. $N$ Engl J Med. 2004;351(2):159-169. doi:10.1056/NEJMra032401

4. Zarjou A, Agarwal A. Sepsis and acute kidney injury. $J$ Am Soc Nephrol. 2011;22(6):999-1006. doi:10.1681/ASN.2010050484

5. Kidney Disease: improving Global Outcomes (KDIGO) Acute Kidney Injury Work Group. KDIGO clinical practice guideline for acute kidney injury. Kidney Int Suppl. 2012;2:1-138. doi:10.1038/ kisup. 2012.1

6. Eyler RF, Mueller BA. Antibiotic dosing in critically ill patients with acute kidney injury. Nat Rev Nephrol. 2011;7(4):226-235. doi:10.1038/nrneph.2011.12

7. Lewis SJ, Mueller BA. Antibiotic dosing in patients with acute kidney injury: "Enough but not too much". J Intensive Care Med. 2016;31(3):164-176. doi:10.1177/0885066614555490

8. Zamoner W, Freitas FM, Garms DSS, Oliveira MG, Balbi AL, Ponce D. Pharmacokinetics and pharmacodynamics of antibiotics in critically ill acute kidney injury patients. Pharmacol Res Perspect. 2016;4(6):e00280. doi:10.1002/prp2.280

9. Hiramatsu K. Vancomycin resistance in Staphylococci. Drug Resist Updat. 1998;1(2):135-150. PMID:16904400. doi:10.1016/S13687646(98)80029-0

10. Rybak MJ, Lomaestro BM, Rotschafer JC, et al. Therapeutic monitoring of vancomycin in adults summary of consensus recommendations from the American Society of Health-System Pharmacists, the Infectious Diseases Society of America, and the Society of Infectious Diseases Pharmacists. Pharmacotherapy. 2009;29(11):1275-1279. PMID:19873687. doi:10.1592/phco.29.11.1275

11. Rybak M, Lomaestro B, Rotschafer JC, et al. Therapeutic monitoring of vancomycin in adult patients: a consensus review of the American Society of Health-System Pharmacists, the Infectious Diseases Society of America, and the Society of Infectious Diseases Pharmacists. Am J Health-Syst Pharm. 2009;66:82-98. doi:10.2146/ ajhp080434

12. Iwamoto T, Kagawa Y, Kojima M. Clinical efficacy of therapeutic drug monitoring in patients receiving vancomycin. Biol Pharm Bull. 2003;26(6):876-879. PMID:12808304 876-9. doi:10.1248/ bpb. 26.876

13. Davis SL, Scheetz MH, Bosso JÁ, Goff DA, Rybak MJ. Adherence to the 2009 consensus guidelines for vancomycin dosing and monitoring practices: a cross-sectional survey of U.S. hospitals. Pharmacotherapy. 2013;33(12):1256-1263. doi:10.1002/phar.1327

14. Ponce D, Zorzenon CDPF, Santos NY, Teixeira UA, Balbi AL. Acute kidney injury in intensive care unit patients: a prospective study on incidence, risk factors and mortality. Rev Bras Ter Intensiva. 2011;23(3):321-326. PMID:23949404. doi:10.1590/ S0103-507X2011000300010

15. Elyasi S, Khalili H, Dashti-Khavidaki S, Mohammadpour A. Vancomycin-induced nephrotoxicity: mechanism, incidence, risk factors and special populations. A literature review. Eur $J$ Clin Pharmacol. 2012;68(9):1243-1255. doi:10.1007/s00228-012-1259-9

16. Gupta A, Biyani M, Khaira A. Vancomycin nephrotoxicity; myths and facts. Neth J Med. 2011;69(9):379-383. PMID:21978980.

17. Bosso JA, Nappi J, Rudisill C, et al. Relationship between vancomycin trough concentrations and nephrotoxicity: a prospective multicenter trial. Antimicrob Agents Chemother. 2011;55(12):5475-5479. doi:10.1128/AAC.00168-11 


\section{Publish your work in this journal}

Infection and Drug Resistance is an international, peer-reviewed openaccess journal that focuses on the optimal treatment of infection (bacterial, fungal and viral) and the development and institution of preventive strategies to minimize the development and spread of resistance. The journal is specifically concerned with the epidemiology of antibiotic resistance and the mechanisms of resistance development and diffusion in both hospitals and the community. The manuscript management system is completely online and includes a very quick and fair peerreview system, which is all easy to use. Visit http://www.dovepress.com/ testimonials.php to read real quotes from published authors.

Submit your manuscript here: https://www.dovepress.com/infection-and-drug-resistance-journal 